\title{
THE ISSUES OF MONUMENTS OF THE BRONZE AGE IN THE WORKS BY V.P. SHILOV
}

\author{
Veronika Ya. Stegantseva \\ Institute for the History of Material Culture, Russian Academy of Sciences, \\ Saint Petersburg, Russian Federation
}

\begin{abstract}
A significant part of works by V. P. Shilov, prominent specialist in the issues of the early Iron Age, are dedicated to the problems of the Bronze Age sites. He was the first to put forward the hypotheses that the pastoral nomadism had existed prior to the Scythian and Sarmatian periods, and that the burials of foundrymen existed in the middle Bronze Age in the steppes of South Russia. The researcher had also developed arguments for the suggested hypotheses.

To prove the first hypothesis, he undertook excavations of burial mounds in open steppe parts, located far away from river valleys. Findings of remnants of carts and cattle bones in the burials of Catacomb and Pit Grave Cultures proved his assumption. For a self-contained argument, the author also used data from geographic, palaeozoologic and ethnographic studies. The latter hypothesis on existence of foundrymen burials was extended and specified by V. S. Bochkarev. Now, aside from these burials, graves of potters, carpenters and arrow-makers are known.

A vast scope of field works and sites excavated had stipulated V. P. Shilov's interest to the subject of attribution and chronology of burial mounds, gravesites and artifacts of the Early and Middle Bronze Age. V. P. Shilov detached and described the Maykop burials in Evdyk mound group, revealed the Archarin horizon, predecessing the ciscaucassian Catacomb Culture, as well as prepared P.S. Rykov's excavation data for publication.

Key words: the Bronze Age, origin of pastoral nomadism, burials of foundrymen, Archarin stage, pre-Caucasian Catacomb Culture.

Citation. Stegantseva V.Ya. The Issues of Monuments of the Bronze Age in the Works by V.P. Shilov. Vestnik Volgogradskogo gosudarstvennogo universiteta. Seriya 4, Istoriya. Regionovedenie. Mezhdunarodnye otnosheniya [Science Journal of Volgograd State University. History. Area Studies. International Relations], 2018, vol. 23, no. 3, pp. 19-28. (in Russian). DOI: https://doi.org/10.15688/jvolsu4.2018.3.2
\end{abstract}

УДК $902 / 908$

Дата поступления статьи: 25.03.2018

ББК 63.4(2)

Дата принятия статьи: 10.04.2018

\section{ПРОБЛЕМАТИКА ПАМЯТНИКОВ ЭПОХИ БРОНЗЫ В ТРУДАХ В.П. ШИЛОВА}

\author{
Вероника Яковлевна Стеганцева \\ Институт истории материальной культуры РАН, г. Санкт-Петербург, Российская Федерация
}

\footnotetext{
Аннотация. В трудах В.П. Шилова, признанного специалиста по проблемам эпохи раннего железа, значительную часть составляли работы по проблематике памятников эпохи бронзы. Именно он поставил и сформулировал гипотезы о происхождении и существовании кочевого скотоводства в более раннюю эпоху, ๘ чем скифскую и сарматскую, и о наличии погребений мастеров-металлургов в эпоху средней бронзы в южнорусских степях и разработал аргументацию в их защиту.

Для доказательства гипотезы о существовании кочевого скотоводства в эпоху ранней и средней бронзы им были предприняты раскопки курганных могильников в открытых степях, удаленных от речных долин. Обнаружение в погребениях ямной и катакомбной культур костных остатков и средств передвижения в виде повозок подтвердили гипотезу. Для более полной аргументации автор привлек данные ученых-географов,

() палеозоологов и этнографов.
} 
Гипотеза о существовании погребений мастеров-металлургов была расширена и уточнена В.С. Бочкаревым. Теперь, кроме вышеупомянутых погребений, известны погребения мастеров-плотников, «стрелоделов» и гончаров.

Большой объем полевых работ и раскопанных памятников обусловил также его интерес к вопросам атрибуции и хронологии могильников, погребений и артефактов эпохи ранней и средней бронзы. В.П. Шилов выделил и описал майкопские погребения в курганной группе Эвдык, выделил архаринский горизонт, предшествующий предкавказской катакомбной культуре, подготовил к публикации материалы раскопок П.С. Рыкова.

Ключевые слова: эпоха бронзы, происхождение кочевого скотоводства, погребения мастеров-литейщиков, архаринский этап, предкавказская катакомбная культура.

Цитирование. Стеганцева В. Я. Проблематика памятников эпохи бронзы в трудах В.П. Шилова // Вестник Волгоградского государственного университета. Серия 4, История. Регионоведение. Международные отношения. - 2018. - Т. 23, № 3. - C. 19-28. - DOI: https://doi.org/10.15688/jvolsu4.2018.3.2

Валентин Павлович Шилов (19171995 гг.) - специалист по курганным культурам южнорусских степей, в течение многих лет руководитель и организатор археологических экспедиций в Нижнем Подонье, Прикубанье и Нижнем Поволжье, а также на территории Калмыкии [3, с. 4].

Труды В.П. Шилова состоят из публикаций многочисленных материалов археологических изысканий, а также работ по палеоэкономике и палеопроизводству. Его вторая монография «Древние скотоводы Калмыцких степей» вышла спустя 14 лет после смерти автора. Немногие археологи удостаиваются такого признания.

В текущем году в Волгоградском университете к 100-летию со дня рождения В.П. Шилова была проведена конференция «Диалог культур: Восток - Запад». Изучая список докладов в программе, можно было бы подумать, что Валентин Павлович занимался проблемами только эпохи раннего железа. Это не так.

Археолог, изучавший проблемы памятников эпохи раннего железа, защитивший в 1951 г. кандидатскую диссертацию на тему «Население Прикубанья конца VI - середины IV века до н. э.: По материалам городищ и грунтовых могильников», с 1954 г. начинает публиковать статьи и заметки по проблемам памятников эпохи бронзы. Как правило, археологи-скифологи и сарматчики, и даже некоторые специалисты по эпохе бронзы уверены в том, что В.П. Шилов занимался проблемами бронзы только в последние десятилетия своей жизни.

Если взглянуть на список работ Валентина Павловича, то обнаружится, что практи- чески всю жизнь он работал с проблемами двух разных эпох. Разумеется, не прав был известный сибирский археолог, бросивший упрек, что Шилов легко менял тематику исследований. Это неверно, Валентин Павлович занимался проблемами разных эпох практически одновременно и практически всю жизнь, владение проблемами разных эпох не мешало, а помогало ему.

В 1962 г. он выступил на 3-м Уральском археологическом совещании с докладом «Происхождение кочевого скотоводства». Он начал свой доклад такими словами: «В античной литературе сохранилось ценное свидетельство о наличии в Северном Причерноморье и Нижнем Поволжье кочевого уклада хозяйства, когда население перемещалось вместе со своими стадами с места на место. Однако греческие историки не ставили вопрос о времени появления кочевого скотоводства». По материалам раскопок, проводившихся с 1954 г. в Волгоградской и Астраханской областях, на основании материалов курганных могильников, находившихся в открытой степи, удаленных на большое расстояние от рек, он выдвинул утверждение, что кочевое скотоводство в Нижнем Поволжье возникло еще во II тыс. до н. э. [12, с. 40-42].

Двумя годами позже эта работа в развернутом виде и с названием «Проблемы освоения степей Нижнего Поволжья в эпоху бронзы» была опубликована в АСГЭ.

Автор, ссылаясь на работы греческих историков Гомера и Гесиода, основой для которых послужили наблюдения греческих колонистов, считал, что развитое кочевое скотоводство у скифов должно было возникнуть 
гораздо раньше и что наличие богатых погребений, свидетельствующих о расслоении в скифском обществе, подтверждает это. Для подкрепления своего предположения автор использовал наблюдения за кочевыми калмыками этнографа Житецкого и свидетельства палеозоолога, определявшего кости из раскопок астраханской экспедиции. В могильниках, выбранных для раскопок Астраханской экспедицией, самыми древними оказались срубные погребения, и В.П. Шилов выдвинул предположение, что в дальнейшем будут найдены и более ранние погребения [13, с. 101]. Оно полностью подтвердилось, и в ямных и катакомбных погребениях, найденных в могильниках в открытой степи, были обнаружены не только кости животных, используемых для разведения при кочевом скотоводстве, но и средства передвижения в виде остатков деревянных повозок и их глиняных моделей.

Валентин Павлович не оставлял эту тему на протяжении практически всей своей жизни.

В 1970 г. в «Украніском історічном журналі» была опубликована работа «Походження кочового скотарства у Схіній Европі» [15, с. 18-25], в 1974-м - в КСИА - статья «К проблеме взаимоотношений кочевых племен и античных городов Северного Причерноморья в сарматскую эпоху» [16]; в 1975-м монография «Очерки по истории древних племен Нижнего Поволжья» [17] и статья «Модели скотоводческих хозяйств степных областей Евразии в эпоху энеолита и раннего бронзового века» в СА [18]; в 1982-м - «Проблема освоения открытых степей Калмыкии от эпохи бронзы до средневековья» в сборнике «Памятники Калмыкии каменного и бронзового веков» [20]; в 1985-м - «Проблемы происхождения кочевого скотоводства в Восточной Европе» в сборнике «Древности Калмыкии» [24]; в 1987-м - «Взаимоотношения номадов Восточной Европы и городов Северного Причерноморья и Передней Азии» в сборнике тезисов конференции «Взаимодействие кочевых культур и древних цивилизаций», проведенной в Алма-Ате [25]; в 1992-м - «К проблеме взаимодействия первобытных земледельческо-скотоводческих племен Евразии» в сборнике тезисов конференции «Северная Евразия от древности до средневековья», проведенной в Санкт-Петербурге [27]; и в 1995-м -
«Древнейшие скотоводы Нижнего и Среднего Поволжья» в тезисах конференции «Проблемы взаимодействия национальных культур», проведенной в Астрахани [28].

В монографии «Очерки по истории древних племен Нижнего Поволжья», вышедшей в 1975 г., первые три главы посвящены публикации материалов трех могильников: Новоникольского I, Новоникольского II и могильника I у с. Верхнее Погромное; следующие пять глав содержат характеристики погребений по группам, а именно ямных, полтавкинских, срубных, савроматских и раннесарматских и среднесарматских. Так вот, в главе IV, названной «Погребения ямной культуры», Валентин Павлович дал краткую характеристику ямных погребений (их было всего 3 и на это ушло меньше страницы). Но на материалах известных к тому времени в Нижнем Поволжье 263 погребений и 200 поселений ямной культуры он дал характеристику производящего хозяйства носителей этой культуры, что заняло примерно 30 страниц.

Шилов собрал и систематизировал данные исследований не только археологов, палеозоологов и этнографов (причем для района, близкого к местам раскопок, Калмыкии), но и данные географов, выделивших 3 зоны, пригодные для различных видов кочевания, и описавших их особенности [17, с. 60-61], и 4 зоны травяного растительного покрова степей Нижнего Поволжья в зависимости от характера почв [17, с. 61-62]. Для воссоздания естественно-географической среды для времен энеолита, бронзы и раннего железа были использованы данные пыльцевого анализа. На основании палинологических данных был сделан вывод о том, что в эпоху бронзы степная растительность была близка к современной $[17$, с. $62-63]$.

По данным палеозоологов, в костных материалах преобладали кости домашних животных. На основании костных остатков в могилах был реконструирован состав стада. В эпоху ямной, предкавказской и полтавкинской культуры примерно три четверти стада составлял мелкий рогатый скот, крупный рогатый скот составлял от 12 до $15 \%$; в эпоху срубной культуры численность мелкого рогатого скота достигала $53 \%$, а крупного - $25 \%$ $[17$, с. $64-65]$. 
Был поднят вопрос об одомашнивании животных разных видов с экскурсами в Западную Европу, Турцию, и Переднюю Азию. Принято утверждение, что «ко времени возникновения ямной культуры население европейских степей уже приручило основные виды домашних животных» [17, с. 72-76].

Характер скотоводства был определен как кочевой, причем для этого был сделан обзор существующих гипотез и этапов развития скотоводства $[17$, с. 71-75]. Поставлен вопрос об освоении открытой степи, в пользу которого говорили находки транспортных средств в погребениях, и сделан вывод, что в эпоху средней бронзы было возможно только кочевое скотоводство $[17$, с. $78-80]$. Выдвинута гипотеза о существовании границ, в пределах которых кочевала хозяйственная единица, и о существовании частной собственности на скот $[17$, с. 88-89] (косвенным образом это подтверждается наличием имущественного расслоения, а также покойников, причиной смерти которых стали стрелы, оставшиеся в теле).

Годом ранее вышла монография Н.Я. Мерперта «Древнейшие скотоводы Волжско-Уральского междуречья». Глава V называлась «Начало производящей экономики в Волжско-Уральских степях» с подзаголовками «Освоение степных пространств», «Основные отрасли производящего хозяйства», «О формах скотоводства древнеямных племен», «Общий характер экономики» [6, с. 98118]. Н.Я. Мерперт был хорошо знаком с работами В.П. Шилова и ссылался не только на опубликованные работы, но и на тезисы докладов Валентина Павловича на заседаниях сектора Средней Азии и Кавказа в 1965 г. и на секции бронзового века пленума Института археологии 18 апреля 1968 г. [6, с. 112].

Кстати Н.Я. Мерперт на основании немногочисленных находок зернотерок считал возможным существование земледелия у ямных племен, В.П. Шилов это утверждение не принял [17, с. 66].

В дальнейшем, как я уже говорила, вышли работы Валентина Павловича о кочевом скотоводстве от эпохи бронзы до эпохи средневековья, на материалах погребений $[18 ; 20]$, и о скотоводстве эпох неолита и энеолита на материалах поселений Нижнего Дона, Калмы- кии, Нижней Волги и Волго-Уральского междуречья [25].

Работы по кочевому скотоводству были одним из направлений интересующей В.П. Шилова темы палеоэкономики и древнего производства.

Другим направлением стали работы о древней металлургии ${ }^{1}$. В 1959 г. в № 60 Материалов и исследований по археологии СССР «Памятники Нижнего Поволжья» вышла статья «О древней металлургии и металлообработке». В ней были опубликованы два погребения мастеров-литейщиков, обнаруженных при раскопках курганов Калиновского могильника. В погребениях были найдены двустворчатые литейные формы с вкладышами для отливки топоров, форма для отливки долот (возможно, тесел), сопла, в том числе орнаментированные, тигли, абразивные инструменты. Комплексы были отнесены к полтавкинской культуре [11, с. 12-19].

В 1966 г. Шилов опубликовал третье погребение литейщика, исследованное в междуречье Волги и Дона, в одном из курганов могильника у станции Жутово [14]. Анализ инвентаря и погребального обряда позволил атрибутировать его как относящееся к манычско-астраханскому варианту катакомбной культуры и дал возможность автору поставить вопрос о наличии местной металлообработки начиная со второй четверти II тыс. до н. э., подчеркнув при этом, что это не умаляет роль северокавказских центров в обеспечении металлическими изделиями степных племен Нижнего Поволжья и Северного Причерноморья в первой половине II тыс. до н. э. [14, с. 88-91].

На эти работы в 1978 г. откликнулся B.C. Бочкарев: коротко описав взгляды Чайлда, Черныха и Шилова на проблему единичности погребений литейщиков (детрибализация мастеров, редкость профессии, начальность процесса узкой специализации литейщиков), он обратил внимание на то, что вышеуказанные авторы решали вопрос вообще, не вникая, к той или другой археологической культуре относятся вышеуказанные погребения, и предложил более правильную постановку вопроса: почему в одних культурах есть погребения с кузнечно-литейными инструментами, а в других, с сотнями раскопанных памятников и развитой металлургией, они отсутствуют? 
Эти соображения, считал В.С. Бочкарев, составляют основу для новой гипотезы: погребения кузнецов-литейщиков возможны в тех культурах (обществах), в которых мастера по обработке металлов не были детрибализированы и погребальный обряд которых фиксировал профессиональную специализацию умерших. Из гипотезы вытекают два ожидания, которые в принципе можно проверить и тем самым хотя бы частично верифицировать саму гипотезу. В тех культурах, где есть эти погребения, следует ожидать: а) тесную связь очага металлообработки и металлургии с культурой; б) открытия могил мастеров из других сфер производства [2, с. 51-52]. Второе из этих ожиданий блестяще оправдалось, и спустя несколько лет появились статьи о мастерахстрелоделах Ю.А. Смирнова [10] и о мастерах-плотниках А.М. Смирнова [9].

Сам Шилов в 1982 г. выступил на всесоюзном симпозиуме «Культурный прогресс в эпоху бронзы и раннего железа» с докладом «Первые ремесленники эпохи бронзы в предкавказских степях», в котором рассказал о том, что погребения мастеров встречены в различных культурах эпохи бронзы, что число их достигло почти 50 , что известны не только литейщики, но и стрелоделы, плотники и гончары, и выдвинул предположение, что производство являлось семейным делом [19, с. 101-103].

Кроме этих ярких направлений, Валентина Павловича занимали вопросы атрибуции изучаемых памятников и необходимых для этого стратиграфии и хронологии. Он начал копать еще в то время, когда мало обращали внимания на стратиграфию. В опубликованных материалах раскопок 50-60-х гг., как правило, не приводятся бровки, а если они есть, то на них не обозначены слои, а только сделаны проекции, которые показывают глубину погребений относительно друг друга. Думаю, что именно комплексы эпохи бронзы обратили внимание Шилова на необходимость выявления стратиграфии и применения более строгой чертежной документации. И в отличие от публикаций И.В. Синицына, публикации В.П. Шилова стали снабжаться подробными чертежами бровок.

В сборнике «Древности Евразии в скифо-сарматское время», несмотря на тематическую направленность, подчеркнутую в на- звании, Шилов поместил статью «Стратиграфическое соотношение "жертвенного места" и погребения 8 кургана 9 группы Три Брата I в Калмыкии» [21, с. 246-251]. Этот памятник был раскопан П.С. Рыковым и частично опубликован И.В. Синицыным. Оба они считали жертвенное место и погребение 8 единым комплексом. Валентин Павлович, как детектив, по дневниковым данным Рыкова установил, что жертвенник находился в верхней части насыпи кургана, сооруженного над погребением 8 , что он находился в яме, нижнюю часть которой удалось проследить. По восстановленной стратиграфии и погребальному инвентарю В.П. Шилов доказал, что жертвенник, скорее всего, является кенотафом предкавказской катакомбной культуры, а погребение 8 относится к раннему этапу предкавказской культуры, архаринскому этапу, синхронному ранней фазе полтавкинской и первому этапу северокавказской культуры, и что они относятся к разным хронологическим горизонтам.

В работе, опубликованной в 1992 г., он изменил атрибуцию погребения литейщиков из Калиновского могильника с полтавкинского на предкавказское [27].

Ведя в течение многих лет раскопки в Калмыкии и в Доно-Волжском междуречье, В.П. Шилов открывал совершенно новые для указанного региона майкопские и новосвободненские погребения с прекрасным инвентарем и прямой стратиграфией [29, с. 160-178] и сталкивался с необходимостью уточнения принятой давно хронологической схемы курганных древностей: ямная, катакомбная, срубная культуры [22, с. 30 31]. Занимаясь вопросами происхождения предкавказской катакомбной культуры Калмыкии, он выделил архаринский этап, предшествующий предкавказской катакомбной культуре, но не успел завершить эту работу. Вызывали критику специалистов как отсутствие строгих признаков, так и объединение в него различных групп, выделенных ранее другими археологами.

Наиболее полный разбор сложившейся ситуации дала Н.И. Шишлина. Она подчеркнула, что выделенный на материалах Калмыкии В.П. Шиловым горизонт больших ям с заплечиками вначале был помещен им между позднеямными и предкавказскими (восточноманычскими) погребениями развитого этапа [31]. Но впоследствии эти погребения были 
объединены Шиловым в общий горизонт с погребениями I, II, III и IV групп В.А. Сафронова, названный архаринским, одновременный с первым этапом северокавказской культуры и полтавкинскими памятниками [23]. Предкавказские катакомбные погребения, представленные в данном регионе восточноманычскими катакомбными, следовали за этим горизонтом, сохраняя некоторые черты предшествующей ямной культуры. Эта схема, по мнению В.П. Шилова, отражала преемственность и хронологическую последовательность ямной и катакомбной культур Калмыкии. При этом архаринский горизонт выглядел достаточно аморфным. Исследователь называл его то предкатакомбным, то 1-м этапом восточноманычской (предкавказской) культуры, относя к катакомбной культуре и 3-й и 4-й группам по классификации В.А. Сафронова [26, c. $17 ; 31$, с. 17].

А.Н. Гей считает, что В.П. Шилов опередил свое время, предложив вместо жесткой хронологической схемы архаринский горизонт, «отмеченный сосуществованием и активным взаимодействием нескольких генетически разнородных групп населения» [3, с. 5].

Я думаю, что Валентину Павловичу просто не хватило времени для того, чтобы разобраться.

М.В. Андреева использовала предложенную схему Шилова [1, с. 70-71]. В.Л. Державин придерживался схемы Сафронова [4, c. 156-158], он критиковал объединение погребений 2, 3, 4-й групп в один горизонт. Стратиграфия, полагал он, свидетельствует о более раннем появлении здесь погребений 2-й группы, а не 3-й или 4-й. Он выступил также против выделения преддонецкого горизонта в Центральном Предкавказье [5, с. 16, 23-25].

Впоследствии в работе Н.И. Шишлиной вместо архаринского горизонта были выделены степная майкопская и северокавказская культуры [31, с. 42-60, 123-148].

В.П. Шилов с большим пиететом относился к работам П.С. Рыкова. В своей последней монографии «Древние скотоводы Калмыцких степей», вышедшей уже после смерти автора, он опубликовал материалы раскопок Рыковым могильников Три Брата I и II, в том числе и его полевые дневники [8, с. 6-10; 30 , с. 97-169].
Если рассматривать труды В.П. Шилова с позиций ретроспективного анализа, то заметно, что примерно с начала 80-х гг. появляются работы, посвященные вопросам хронологии и атрибуции памятников. До этого времени проблематика эпохи бронзы касалась в основном вопросов производящего хозяйства. Мне кажется, этот перекос обусловлен реалиями времени, в котором В.П. Шилов получил образование. В то время историю представляли в виде сменяющих друг друга экономических формаций, и в археологии господствовали те же позиции.

Хочу напомнить несколько слов из совместной работы В.П. Шилова и Н.Я. Мерперта «Бронзовый век Поволжья: исследования П.С. Рыкова и современное состояние проблемы» [7, с. 24-32]: «Стадия эта (речь о полтавкинской ступени. - В. C.) представлена рядом исторически (а в определенных случаях и генетически) связанных культурных групп, находившихся в постоянном взаимодействии. Последнее предопределяет крайнюю сложность и дискуссионность проблематики этого периода, имеющей, вместе с тем, решающее значение для разработки вопросов формирования гигантских культурно-исторических областей последующего периода - позднего бронзового века. И если сейчас сложность эта постепенно преодолевается, то в этом огромная роль тех импульсов, тех направлений, которые даны работами П.С. Рыкова».

Практически те же слова мы можем сказать и в отношении В.П. Шилова.

Не каждому археологу удается обнаружить, сформулировать и оформить новое направление в науке. В.П. Шилов смог сделать это дважды.

\section{ПРИМЕЧАНИЕ}

${ }^{1}$ Пользуюсь случаем выразить благодарность В.С. Бочкареву за консультацию и воспоминания о совместной работе с В.П. Шиловым.

\section{СПИСОК ЛИТЕРАТУРЫ}

1. Андреева, М. В. Курганы у Чограйского водохранилища / М. В. Андреева // Древности Ставрополья. - М. : Наука, 1989. - С. 24-124.

2. Бочкарев, В. С. Погребения литейщиков эпохи бронзы (методологический пересмотр) / 
В. С. Бочкарев // Проблемы археологии. - Л. : Изд-во ЛГУ, 1978. - С. $48-53$.

3. Гей, А. Н. Валентин Павлович Шилов и его книга / А. Н. Гей // В. П. Шилов. Древние скотоводы калмыцких степей. - Элиста : Герел, 2009. - С. 4-5.

4. Державин, В. Л. Погребения эпохи бронзы из курганов у хутора Веселая Роща / В. Л. Державин // Древности Ставрополья. - М. : Наука, 1989.C. $125-194$.

5. Державин, В. Л. Степное Ставрополье в эпоху ранней и средней бронзы / В. Л. Державин. М. : ИА АН СССР, 1991. - $186 \mathrm{c}$.

6. Мерперт, Н. Я. Древнейшие скотоводы Волжско-Уральского междуречья / Н. Я. Мерперт. -М. : Наука, 1974. - 167 c.

7. Мерперт, Н. Я. Бронзовый век Поволжья: исследования П. С. Рыкова и современное состояние проблемы / Н. Я. Мерперт, В. П. Шилов // Археология Восточно-Европейской лесостепи. Вып. 1.Саратов : Изд-во СГУ, 1989. - С. 24-32.

8. Очир-Горяева, М. А. ВкладВ.П. Шилова в развитие археологической науки Калмыкии / М. А. ОчирГоряева // В. П. Шилов. Древние скотоводы калмыцких степей. - Элиста : Герел, 2009. - С. 6-10.

9. Смирнов, А. М. Создатели повозок эпохи бронзы в Понто-Каспийском ареале: идентификация профессиональных инструментов и погребений мастеров / А. М. Смирнов // Евразия. Этнокультурное взаимодействие и исторические судьбы : тезисы докладов. - М. : РГГУ, 2004.C. $117-120$.

10. Смирнов, Ю. А. Погребения мастеров изготовителей древков и кремневых наконечников стрел / Ю. А. Смирнов // Древности Дона. - М. : Наука, 1983. - С. 164-187.

11. Шилов, В. П. О древней металлургии и металлообработке в Нижнем Поволжье / В. П. Шилов // Материалы и исследования по археологии СССР. № 60. - М. : Наука, 1959. - С. 11-38.

12. Шилов, В. П. Происхождение кочевого скотоводства / В. П. Шилов // Тезисы докладов 3-го Уральского археологического совещания в г. Казани. -Уфа : Институт истории, языка и литературы БФАНСССР, 1962. - С. 40-42.

13. Шилов, В. П. Проблемы освоения степей Нижнего Поволжья в эпоху бронзы / В. П. Шилов // Археологический сборник Государственного Эрмитажа. Вып. 6. - Л. : Изд-во Гос. Эрмитажа, 1964. C. 86-102.

14. Шилов, В. П. Погребение литейщика катакомбной культуры в Нижнем Поволжье / В. П. Шилов // Краткие сообщения Института археологии. 1966. - № 106. - С. 88-91.

15. Шилов, В. П. Походження кочового скотарства у Схіній Европі / В. П. Шилов // Украінский історичний журнал. - Киів, 1970. - № 2. - С. 18-25.
16. Шилов, В. П. К проблеме взаимоотношений кочевых племен и античных городов Северного Причерноморья в сарматскую эпоху / В. П. Шилов // Краткие сообщения Институга археологии. 1974. - Вып. 138. - С. 6-65.

17. Шилов, В. П. Очерки по истории древних племен Нижнего Поволжья / В. П. Шилов - Л. : Наука, 1975. - 208 с.

18. Шилов, В. П. Модели скотоводческих хозяйств степных областей Евразии в эпоху энеолита и раннего бронзового века / В. П. Шилов // Советская археология. - 1975. - № 1. - С. 5-16.

19. Шилов, В. П. Первые ремесленники эпохи бронзы в предкавказских степях / В. П. Шилов // Культурный процесс в эпоху бронзы и раннего железа : тезисы докладов. - Ереван : Изд-во АН АССР, 1982. C. 101-103.

20. Шилов, В. П. Проблема освоения открытых степей Калмыкии от эпохи бронзы до средневековья / В. П. Шилов // Памятники Калмыкии каменного и бронзового веков. - Элиста : Калмыцкий НИИ истории, филологии и экономики при Совете Министров Калмыцкой АССР, 1982. - С. 24-53.

21. Шилов, В. П. Стратиграфическое соотношение «жертвенного места» и погребения 8 кургана 9 группы Три Брата I в Калмыкии / В. П. Шилов // Древности Евразии в скифо-сарматское время. М. : Наука, 1984. - С. 246-251.

22. Шилов, В. П. Курган 6 урочища БичкинБулук и проблема хронологии начала средней бронзы в Калмыкии / В. П. Шилов // Советская археология - 1985. - № 2. - С. 17-33.

23. Шилов, В. П. Курганный могильник у с. Цаца / В. П. Шилов // Древности Калмыкии. - Элиста : Калмыцкий НИИ истории, филологии и экономики при Совете Министров Калмыцкой АССР, 1985. C. 94-157.

24. Шилов, В. П. Проблемы происхождения кочевого скотоводства в Восточной Европе / В. П. Шилов // Древности Калмыкии. - Элиста : Калмыцкий НИИ истории, филологии и экономики при Совете Министров Калмыцкой АССР, 1985. - С. 23-33.

25. Шилов, В. П. Взаимоотношения номадов Восточной Европы и городов Северного Причерноморья и Передней Азии / В. П. Шилов // Взаимодействие кочевых культур и древних цивилизаций : тез. докл. - Алма-Ата : Наука, 1987. - С. 128-129.

26. Шилов, В. П. К хронологии нижнего горизонта донецкой катакомбной культуры / В. П. Шилов // Археологические исследования в Калмыкии. Элиста : Калмыцкий НИИ истории, филологии и экономики при Совете Министров Калмыцкой ACCP, 1987.- C. 4-28.

27. Шилов, В. П. К проблеме взаимодействия первобытных земледельческо-скотоводческих племен Евразии / В. П. Шилов // Северная Евразия от 
древности до средневековья : тез. конф. к 90-летию М. П. Грязнова. - СПб. : ИИМК РАН, 1992. - С. 26-27.

28. Шилов, В. П. Древнейшие скотоводы Нижнего и Среднего Поволжья / В. П. Шилов // Проблемы взаимодействия национальных культур : тез. докл. Ч. 2. - Астрахань : Изд-во Астраханского пед. ин-та, 1995. - С. 69-70.

29. Шилов, В. П. Погребения энеолита-ранней бронзы могильника Эвдык / В. П. Шилов, Р. С. Багаутдинов // Проблемы древней истории Северного Прикаспия. - Самара : Изд-во Самарского ГПУ, 1998. - C. 160-178.

30. Шилов, В. П. Древние скотоводы Калмыцких степей / В. П. Шилов. - Элиста : Герел, 2009. $304 \mathrm{c}$.

31. Шишлина Н. И. Северо-Западный Прикаспий в эпоху бронзы (V-III тыс. до н. э.) / Н. И. Шишлина // Труды ГИМ. - Вып. 165. - М. : НИО ГИМ, 2007. $-400 \mathrm{c}$.

\section{REFERENCES}

1. Andreeva M.V. Kurgany u Chograyskogo vodokhranilishcha [Mounds near the Chogray Reservoir]. Drevnosti Stavropolya [Antiquities of the Stavropol Region]. Moscow, Nauka Pul., 1989, pp. 24-124.

2. Bochkarev V.S. Pogrebeniya liteyshchikov epokhi bronzy (metodologicheskiy peresmotr) [The Burials of the Bronze Age Foundrymen (Methodological Review)]. Problemy arkheologii [Problems of Archaeology]. Leningrad, Izd-vo LGU, 1978, pp. 48-53.

3. GeyA.N. Valentin Pavlovich Shilov i ego kniga [Valentin Pavlovich Shilov and His Book]. V. P. Shilov. Drevnie skotovody kalmytskikh stepey [Valentin Shilov. Ancient Pastoralists of Kalmyk Steppes]. Elista, Gerel Publ., 2009, pp. 4-5.

4. Derzhavin V.L. Pogrebeniya epokhi bronzyiz kurganov u khutora Veselaya Roshcha [Burials of the Bronze Age from the Mounds near the Veselaya Roshcha Hamlet]. Drevnosti Stavropolya [Antiquities of the Stavropol Region]. Moscow, Nauka Publ., 1989, pp. 125-194.

5. Derzhavin V.L. Stepnoe Stavropolye vepokhu ranney $i$ sredney bronzy [The Steppe Stavropol Region in the Early and Middle Bronze Age]. Moscow, Izd-vo IA AN SSSR, 1991. 186 p.

6. Merpert N.Ya. Drevneyshie skotovody Volzhsko-Uralskogo mezhdurechya [The Ancient Cattle Breeders of the Volga-Ural Interfluve]. Moscow, Nauka Publ., 1974. 167 p.

7. Merpert N.Ya., Shilov V.P. Bronzovyy vek Povolzhya: issledovaniya P. S. Rykova i sovremennoe sostoyanie problemy [The Bronze Age of the Volga
Region: the Study by P.S. Rykov and the Modern Research into the Problem]. Arkheologiya VostochnoEvropeyskoy lesostepi. Vyp. 1. [Archaeology of the East European Forest-Steppe Zone. Iss. 1]. Saratov, Izd-vo SGU, 1989, pp. 24-32.

8. Ochir-Goryaeva M.A. Vklad V.P. Shilova v razvitie arkheologicheskoy nauki Kalmykii [The Contribution of V. P. Shilov in the Development of the Archaeological Studies in the Republic of Kalmykia]. V. P. Shilov. Drevnie skotovody kalmytskikh stepey [Valentin Shilov. Ancient Pastoralists of Kalmyk Steppes]. Elista, Gerel Publ., 2009, pp. 6-10.

9. Smirnov A.M. Sozdateli povozok epokhi bronzy v Ponto-Kaspiyskom areale: identifikatsiya professionalnykh instrumentov i pogrebeniy masterov [The Creators of Bronze Age Carts in the PontoCaspian Area: Identification of Professional Tools and Burials of Masters]. Evraziya. Etnokulturnoe vzaimodeystvie $i$ istoricheskie sudby. Tezisy dokladov [Eurasia. Ethno-Cultural Interaction and Historical Fates. Reports' Theses]. Moscow, RGGU Publ., 2004, pp. 117-120.

10. Smirnov Yu.A. Pogrebeniya masterovizgotoviteley drevkov i kremnevykh nakonechnikov strel [The Burials of Masters-Manufacturers of Shafts and Flint Arrowheads]. Drevnosti Dona [Antiquities of the Don River]. Moscow, Nauka Publ., 1983, pp. 164-187.

11. Shilov V.P. O drevney metallurgii i metalloobrabotke v Nizhnem Povolzhye [On the Ancient Metallurgy and Metalworking in the Lower Volga Region]. Materialy i issledovaniya po arkheologii SSSR [Materials and Research on the Archaeology of the USSR]. Moscow, Nauka publ., 1959, no. 60, pp. 11-38.

12. Shilov V.P. Proiskhozhdenie kochevogo skotovodstva [The Origin of Nomadic Cattle Breeding]. Tezisy dokladov 3-go Uralskogo arkheologicheskogo soveshchaniya $v g$. Kazani [Theses of Reports of the $3^{\text {rd }}$ Ural Archaeological Meeting in Kazan]. Ufa, Institut istorii, yazyka i literatury BFAN SSSR, 1962, pp. 40-42.

13. Shilov V.P. Problemy osvoeniya stepey Nizhnego Povolzhya v epokhu bronzy [The Problems of Steppes Colonization in the Lower Volga Region in the Bronze Age]. Arkheologicheskiy sbornik Gosudarstvennogo Ermitazha [Archaeological Digest of the State Hermitage]. Leningrad, Izd-vo Gosudarstvennogo Ermitazha, 1964, no. 6, pp. 86-102.

14. Shilov V.P. Pogrebenie liteyshchika katakombnoy kultury v Nizhnem Povolzhye [The Burial of the Catacomb Culture's Foundryman in the Lower Volga Region]. Kratkiye soobshcheniya Instituta arkheologii [Brief Reports of the Institute of Archaeology], 1966, no. 106, pp. 88-91.

15. Shilov V.P. The Origin of Nomadic Cattle Breeding in Eastern Europe. Ukrainskiy istorichniy 
zhurnal [Ukrainian historical journal], 1970, no. 2, pp. 18-25. (in Ukrainian).

16. Shilov V.P. K probleme vzaimootnosheniy kochevykh plemen i antichnykh gorodov Severnogo Prichernomorya $v$ sarmatskuyu epokhu [On the Relations of Nomadic Tribes and Ancient Cities of the Northern Black Sea Region in the Sarmatian Age]. Kratkie soobshcheniya Instituta arkheologii [Brief Reports of the Institute of Archaeology], 1974, no. 138, pp. 6-65.

17. Shilov V.P. Ocherki po istorii drevnikh plemen Nizhnego Povolzhya [Essays on the History of the Ancient Tribes of the Lower Volga Region]. Leningrad, Nauka Publ., 1975. 208 p.

18. Shilov V.P. Modeli skotovodcheskikh khozyaystv stepnykh oblastey Evrazii v epokhu eneolita i rannego bronzovogo veka [The Models of Cattle-Breeding Farms in the Steppe Regions of Eurasia during the Eneolithic and Early Bronze Age]. Sovetskaya arkheologiya [Soviet Archaeology], 1982, no. 1, pp. 5-16.

19. Shilov V.P. Pervye remeslenniki epokhi bronzy v predkavkazskikh stepyakh [The First Artisans of the Bronze Age in the pre-Caucasian Steppes]. Kulturnyy protsess v epokhu bronzy i rannego zheleza [Cultural Process in the Bronze and Early Iron Ages]. Erevan, Izd-vo AN ASSR, 1982, pp. 101-103.

20. Shilov V.P. Problema osvoeniya otkrytykh stepey Kalmykii ot epokhi bronzy do srednevekovya [The Problem of Colonization of Open Steppes of Kalmykia from the Bronze Age to the Middle Ages]. Pamyatniki Kalmykii kamennogo i bronzovogo vekov [Monuments of Kalmykia in the Stone and Bronze Ages]. Elista, Kalm. NII istorii, filologii i ekonomiki pri Sov. ministrov Kalm. ASSR, 1982, pp. 24-53.

21. Shilov V.P. Stratigraficheskoe sootnoshenie «zhertvennogo mesta» i pogrebeniya 8 kurgana 9 gruppy Tri Brata I v Kalmykii [Stratigraphic Correlation of a "Sacrificial Place" and Burial 8 of Mound 9 of the Group Three Brothers I in Kalmykia]. Drevnosti Evrazii [Antiquities of Eurasia]. Moscow, Nauka Publ., 1984, pp. 246-251.

22. Shilov V.P. Kurgan 6 urochishcha BichkinBuluk i problema khronologii nachala sredney bronzy v Kalmykii [Mound 6 of Tract Bichkin-Buluk and the Problem of Chronology of the Middle Bronze in Kalmykia]. Sovetskaya arkheologiya [Soviet Archaeology], 1985, no. 2, pp. 17-33.

23. Shilov V.P. Kurgannyy mogilnik u s. Tsatsa [A Burial Mound near the Village Tsatsa]. Drevnosti Kalmykii [Antiquities of Kalmykia]. Elista, Kalm. NII istorii, filologii i ekonomiki pri Sov. ministrov Kalm. ASSR, 1985, pp. 94-157.
24. Shilov V.P. Problemy proiskhozhdeniya kochevogo skotovodstva $\mathrm{v}$ Vostochnoy Evrope [The Problems of the Origin of Nomadic Cattle Breeding in Eastern Europe]. Drevnosti Kalmykii [Antiquities of Kalmykia]. Elista, Kalm. NII istorii, filologii i ekonomiki pri Sov. ministrov Kalm. ASSR, 1985, pp. 23-33.

25. Shilov V.P. Vzaimootnosheniya nomadov Vostochnoy Evropy i gorodov Severnogo Prichernomorya i Peredney Azii [Relations of the Nomads of Eastern Europe and the Cities of the Northern Black Sea and Central Asia]. Vzaimodeystvie kochevykh kultur i drevnikh tsivilizatsiy. Tezisy dokladov [Interaction of Nomadic Cultures and Ancient Civilizations. Reports' Theses]. Alma-Ata, Nauka Publ., 1987, pp. 128-129.

26. Shilov V.P. K khronologii nizhnego gorizonta donetskoy katakombnoy kultury [On the Chronology of the Lower Horizon of the Donetsk Catacomb Culture]. Arkheologicheskie issledovaniya $v$ Kalmykii [Archaeological Research in Kalmykia]. Elista, Kalm. NII istorii, filologii i ekonomiki pri Sov. ministrov Kalm. ASSR, 1987, pp. 4-28.

27. Shilov V.P. K probleme vzaimodeystviya pervobytnykh zemledelchesko-skotovodcheskikh plemen Evrazii [On the Interaction of Primitive Agricultural and Pastoral Tribes of Eurasia]. Severnaya Evraziya ot drevnosti do srednevekovya. Tezisy konferentsii k 90-letiyu M.P. Gryaznova [Northern Eurasia from Antiquity to the Middle Ages. Proceedings of the Conference Devoted to the $90^{\text {th }}$ Anniversary of M.P. Gryaznov]. Saint Petersburg, IIMK RAN Publ., 1992, pp. 26-27.

28. Shilov V.P. Drevneyshie skotovody Nizhnego i Srednego Povolzhya [Ancient Pastoralists of the Lower and Middle Volga Region]. Problemy vzaimodeystviya natsionalnykh kultur. Tezisy dokladov. Ch. 2. [The Problems of Interaction of National Cultures. Reports' Theses. Part 2]. Astrakhan, Izd-vo Astrakhanskogo ped. in-ta, 1995, pp. 69-70.

29. Shilov V.P., Bagautdinov R.S. Pogrebeniya eneolita-ranney bronzy mogilnika Evdyk [Burials of Eneolithic-Early Bronze Age Burial Mound Evdyk]. Problemy drevney istorii Severnogo Prikaspiya [Problems of the Ancient History of the Northern Caspian Region]. Samara, Izd-vo Samarskogo GPU, 1998, pp. 160-178.

30. Shilov V.P. Drevnie skotovody kalmytskikh stepey [The Ancient Pastoralists of Kalmyk Steppes]. Elista, Gerel Publ., 2009. 304 p.

31. Shishlina N.I. Severo-Zapadnyy Prikaspiy v epokhu bronzy (V-III tys. do n.e.) [The North-Western Caspian Region in the Bronze Age $\left(5^{\text {th }}-3^{\text {rd }}\right.$ millenia BC)]. Trudy GIM [Proceedings of GIM]. Moscow, NIO GIM, 2007, iss. $165.400 \mathrm{p}$. 


\section{Information about the Author}

Veronika Ya. Stegantseva, Junior Researcher, Department of Archaeology of Central Asia and the Caucasus, Institute for the History of Material Culture, Russian Academy of Sciences, Dvortsovaya Emb., 18, 191186 Saint Petersburg, Russian Federation, veronika_stegantseva@mail.ru, https://orcid.org/00000003-3130-0359

\section{Информация об авторе}

Вероника Яковлевна Стеганцева, младший научный сотрудник отдела археологии Центральной Азии и Кавказа, Институт истории материальной культуры РАН, Дворцовая набережная, 18, 191186 г. Санкт-Петербург, Российская Федерация, veronika_stegantseva@mail.ru, https:// orcid.org/0000-0003-3130-0359 